\title{
Vanillic Acid Restores Coenzyme Q Biosynthesis and ATP Production in Human Cells Lacking COQ6
}

\author{
Manuel J. Acosta Lopez, ${ }^{1,2}$ Eva Trevisson, ${ }^{1,2}$ Marcella Canton, ${ }^{2,3}$ Luis Vazquez-Fonseca, ${ }^{1,2}$ \\ Valeria Morbidoni, ${ }^{1,2}$ Elisa Baschiera, ${ }^{1,2}$ Chiara Frasson, ${ }^{2}$ Ludovic Pelosi, ${ }^{4}$ \\ Bérengère Rascalou, ${ }^{4}$ Maria Andrea Desbats, ${ }^{1,2}$ María Alcázar-Fabra, ${ }^{5}$ José Julián Ríos, \\ Alicia Sánchez-García, ${ }^{6}$ Giuseppe Basso, ${ }^{2,7}$ Placido Navas, ${ }^{5}$ Fabien Pierrel, ${ }^{4}$ \\ Gloria Brea-Calvo $\left(\mathbb{D},{ }^{5}\right.$ and Leonardo Salviati ${ }^{1,2}$ \\ ${ }^{1}$ Clinical Genetics Unit, Department of Women's and Children's Health, University of Padova, Italy \\ ${ }^{2}$ Istituto di Ricerca Pediatrica (IRP) Città della Speranza, Padova, Italy \\ ${ }^{3}$ Department of Biomedical Sciences, University of Padova, Italy \\ ${ }^{4}$ Univ. Grenoble Alpes, CNRS, Grenoble INP, TIMC-IMAG, Grenoble, France \\ ${ }^{5}$ Centro Andaluz de Biología del Desarrollo, Universidad Pablo de Olavide and CIBERER, Sevilla, Spain \\ ${ }^{6}$ Laboratorio de Espectrometría de Masas, Instituto de la Grasa (CSIC), Universidad Pablo de Olavide, Sevilla, Spain \\ ${ }^{7}$ Hematology-Oncology Laboratory Department of Women's and Children's Health, University of Padova, Italy
}

Correspondence should be addressed to Gloria Brea-Calvo; gbrecal@upo.es and Leonardo Salviati; leonardo.salviati@unipd.it

Received 3 February 2019; Revised 30 April 2019; Accepted 26 May 2019; Published 10 July 2019

Guest Editor: Livia Hool

Copyright @ 2019 Manuel J. Acosta Lopez et al. This is an open access article distributed under the Creative Commons Attribution License, which permits unrestricted use, distribution, and reproduction in any medium, provided the original work is properly cited.

\begin{abstract}
Coenzyme Q (CoQ), a redox-active lipid, is comprised of a quinone group and a polyisoprenoid tail. It is an electron carrier in the mitochondrial respiratory chain, a cofactor of other mitochondrial dehydrogenases, and an essential antioxidant. CoQ requires a large set of enzymes for its biosynthesis; mutations in genes encoding these proteins cause primary CoQ deficiency, a clinically and genetically heterogeneous group of diseases. Patients with CoQ deficiency often respond to oral $\mathrm{CoQ}_{10}$ supplementation. Treatment is however problematic because of the low bioavailability of $\mathrm{CoQ}_{10}$ and the poor tissue delivery. In recent years, bypass therapy using analogues of the precursor of the aromatic ring of CoQ has been proposed as a promising alternative. We have previously shown using a yeast model that vanillic acid (VA) can bypass mutations of COQ6, a monooxygenase required for the hydroxylation of the $\mathrm{C} 5$ carbon of the ring. In this work, we have generated a human cell line lacking functional COQ6 using CRISPR/Cas9 technology. We show that these cells cannot synthesize CoQ and display severe ATP deficiency. Treatment with VA can recover CoQ biosynthesis and ATP production. Moreover, these cells display increased ROS production, which is only partially corrected by exogenous CoQ, while VA restores ROS to normal levels. Furthermore, we show that these cells accumulate 3-decaprenyl-1,4-benzoquinone, suggesting that in mammals, the decarboxylation and C1 hydroxylation reactions occur before or independently of the C5 hydroxylation. Finally, we show that COQ6 isoform c (transcript NM_182480) does not encode an active enzyme. VA can be produced in the liver by the oxidation of vanillin, a nontoxic compound commonly used as a food additive, and crosses the blood-brain barrier. These characteristics make it a promising compound for the treatment of patients with CoQ deficiency due to COQ6 mutations.
\end{abstract}

\section{Introduction}

Coenzyme $\mathrm{Q}(\mathrm{CoQ})$ is a key component of the mitochondrial respiratory chain $(\mathrm{RC})$ where it shuttles electrons from complexes I and II to complex III. It is also a cofactor of other mitochondrial dehydrogenases and of uncoupling proteins, an antioxidant, and a modulator of the mitochondrial permeability transition pore [1]. CoQ is comprised of a 
quinone group and of a polyisoprenoid tail, which varies in length in different species: ten isoprene units in humans $\left(\mathrm{CoQ}_{10}\right)$, nine in mice $\left(\mathrm{CoQ}_{9}\right)$, and six in yeast $\left(\mathrm{CoQ}_{6}\right)$. The CoQ biosynthetic pathway is still incompletely characterized, especially in higher eukaryotes [2]. The biogenesis of the isoprene tail begins in the cytosol through the mevalonate pathway, sharing its initial steps with cholesterol biosynthesis. The individual isopentyl diphosphate units produced in these pathways are then joined together to form the alltrans polyprenyl tail by COQ1 (in yeast) and PDSS1 and PDSS2 (in mammals) within mitochondria. The quinone group is synthesized from tyrosine through a poorly characterized set of reactions that produce 4-hydroxybenzoate (4-HB) $[3,4] .4-\mathrm{HB}$ is then joined to the polyisoprene tail by COQ2, an integral protein of the mitochondrial inner membrane [5]. Subsequent biosynthetic steps occur within the mitochondrial matrix and are catalyzed by a set of enzymes that modify the quinone ring. In eukaryotes, these enzymes form a multiprotein complex associated with the inner mitochondrial membrane [6]. This complex is still poorly characterized in mammals, and the precise sequence of reactions is not known [2].

Among the different genes coding the components of this complex, COQ6 encodes a FAD-dependent monooxygenase responsible for the addition of the hydroxyl group in position C5 of the quinone ring [7].

CoQ biosynthesis is relevant for human diseases because mutations in genes involved in CoQ biosynthesis cause primary CoQ deficiency, a clinically heterogeneous group of disorders. In particular, patients with mutations in COQ6 present with steroid-resistant nephrotic syndrome (SRNS) associated with sensorineural deafness and a variable degree of encephalopathy [8]. CoQ-deficient patients respond to oral $\mathrm{CoQ}_{10}$ supplementation, making this one of the few treatable mitochondrial disorders [9]. Therapy is however still problematic; $\mathrm{CoQ}_{10}$ has a low bioavailability and very high doses are required; moreover, not all patients seem to respond adequately to treatment. Long-term follow-up data in humans are not available, but in a mouse model of CoQ deficiency, which recapitulates the human renal phenotype, progression of the disease is observed in the long term, despite treatment [10].

A possible solution to this problem is bypass therapy using analogues of 4 - $\mathrm{HB}$, which provide the defective chemical group and can reactivate endogenous CoQ biosynthesis $[11,12]$. In the case of COQ6, it has been shown in yeast mutants that $4-\mathrm{HB}$ analogues such as vanillic acid (VA) or 3-4-dihydroxybenzoate, which already harbor a hydroxyl or methoxyl group in position 5 of the ring, may bypass the COQ6 defect and restore endogenous biosynthesis [7]. For this to occur, however, the mutants must retain structural stability, in order to allow formation of the multienzyme complex (in yeast, the presence of each of its protein components is required for the stability of the complex). COQ6 mutations found in human patients have these characteristics, and when expressed in $S$. cerevisiae, they are responsive to $\mathrm{VA}$ [13], making this compound an attractive alternative for patient treatment.
In this work, we report the generation of a cell line lacking functional COQ6, which was used to test the effect of VA supplementation.

\section{Materials and Methods}

2.1. Cell Culture and Reagents. HEK 293 cells were cultured at $37^{\circ} \mathrm{C}$ using DMEM $4.5 \mathrm{~g} / \mathrm{L}$ glucose, L-glutamine $(6 \mathrm{mM})$ $\left(\mathrm{Gybco}^{\mathrm{TM}}\right)$ supplemented with sodium pyruvate solution (1 mM) (Sigma), an antibiotic/antimycotic solution (Sigma), uridine $(10 \mu \mathrm{M})$ (Sigma), and 10\% fetal bovine serum (FBS) $\left(G_{y b c o}{ }^{\mathrm{TM}}\right)$. When required, supplemental CoQ prediluted in ethanol $100 \%$ was added to the medium at a final concentration of $100 \mu \mathrm{M}$ (coenzyme $\mathrm{Q}_{10}$, $\geq 98 \%$, HPLC, Sigma) and supplemental vanillic acid was added at a final concentration of $500 \mu \mathrm{M}$ (vanillic acid, $\geq 97 \%$, HPLC, Sigma.). For all biochemical assays, cells were incubated for 48 hours in DMEM containing $2 \mathrm{mM}$ glucose and 5\% FBS, to force mitochondrial respiration.

2.2. Generation of CRISPR Knockout Cell Lines. The CRISPR/Cas9 constructs were purchased from transOMIC technologies. We performed transfection by using Lipofectamine 2000 (Life Technologies), according to the manufacturer's instructions. Two pCLIP-All-EFS vectors, which express Cas 9 and the target gRNAs, together with the puromycin resistance gene (TEVH-1164665: 3' -TCCTGTAGA GAACCGTCACT-5'; TEVH-1097523: $3^{\prime}$-CTAGGGTAA TATGAACCCAA- $5^{\prime}$ ), were cotransfected into HEK293 cells. Cells were incubated in medium with $1,5 \mu \mathrm{g} / \mathrm{mL}$ puromycin for selection. Cell clones were obtained by cell sorting into 96-well plates, cultured until confluence, and duplicated for genotyping PCR. Culture media were supplemented with $\mathrm{CoQ}_{10}$ and uridine as described [14]. Three positive clones were expanded and mixed $(1: 1: 1)$ to obtained a homogeneous cell population.

2.3. Construction and Transfection of Lentiviral Vectors. The coding sequence of human COQ6 isoform $a$ and isoform $c$, the mutated sequence COQ6 G255R, and a negative control expression sequence were transferred into the lentiviral expression plasmid (pLenti6/V5-DEST ${ }^{\mathrm{TM}}$ Gateway $^{\mathrm{TM}}$ Vector, Invitrogen). To generate lentiviral particles, vectors were cotransfected with packaging vectors (ViraPower Packaging Mix, Invitrogen) into HEK293-FT cells using Lipofectamine 2000 (Life Technologies). Culture supernatants were harvested on day 3 and used to transduce HEK293 COQ6KO cells. Selection was carried out as described [15].

2.4. GFP Fusion Vectors. A COQ6_Iso_c-GFP fusion gene was constructed using the pEGFP-N1 as previously reported [8], except that the forward primer employed was specific for COQ6 isoform $c$ ( $5^{\prime}$-TCTAAGCTTGCTATGCGGGGC CAGGGTCCACC- $3^{\prime}$ ). As the PCR template, we employed the plasmid generated for the lentiviral construct. The pEGFPN1-COQ6_Iso_c was used to transiently transfect HeLa cells stably expressing mtRFP seeded on glass coverslips [16]. 48 hours after transfection, cells were examined using a Zeiss Axio Imager M2 fluorescence microscope. 
2.5. Immunoblot Assay. Standard techniques were employed for SDS-PAGE and Western blotting to PVDF membranes using the antibody COQ6 12481-1-AP (Proteintech). Peroxidase-conjugated anti-rabbit IgG was used as secondary antibodies (Santa Cruz). Visualization of antibody protein complexes was achieved by enhanced chemiluminescence (LiteAblot Turbo, EuroClone) and the ChemiDoc ${ }^{\mathrm{TM}}$ XRS+ System (Bio-Rad).

2.6. Lipid Extraction and HPLC Analysis. Harvested cells ( $1 \mathrm{mg}$ protein) were resuspended in $0.3 \mathrm{~mL}$ of a $0.15 \mathrm{M} \mathrm{KCl}$ solution. Then, $200 \mu \mathrm{L}$ glass beads, $10 \mu \mathrm{L}$ of a $5 \mu \mathrm{M}$ UQ8 standard solution, and $3 \mathrm{~mL}$ methanol were added. The tubes were vortexed for $1 \mathrm{~min}, 2 \mathrm{~mL}$ petroleum ether $\left(40-60^{\circ}\right.$ boiling range) was added, and vortex was repeated for $1 \mathrm{~min}$. The tubes were centrifuged at $700 \mathrm{rpm}$ for $1 \mathrm{~min}$, the upper phase was collected, and the methanol phase was extracted again with $2 \mathrm{~mL}$ petroleum ether. Both petroleum ether phases were combined and dried under a nitrogen flow, and the lipid extracts were resuspended in $200 \mu \mathrm{L}$ ethanol. HPLC analysis was conducted essentially as described [17] with the following modifications. Samples corresponding to $0.2 \mathrm{mg}$ protein were injected onto the $\mathrm{C} 18$ column, and separation was obtained at a flow rate of $1 \mathrm{~mL} / \mathrm{min}$ with a mobile phase composed of $25 \%$ isopropanol, $45 \%$ methanol, $20 \%$ ethanol, and $10 \%$ of a solution composed of $90 \%(v / v)$ isopropanol, $10 \%(v / v) 1 \mathrm{M}$ ammonium acetate, and $0.1 \%$ $(v / v)$ formic acid. The precolumn electrode (5020 Guard Cell, Thermo) was set either at $+650 \mathrm{mV}$ (oxidizing mode) or at $-650 \mathrm{mV}$ (reducing mode). Mass spectrometry detection was conducted in positive mode with electrospray ionization, probe temperature of $400^{\circ} \mathrm{C}$, and cone voltage of $80 \mathrm{~V}$. 4$\mathrm{HP}_{10}$ was detected with single-ion monitoring at $\mathrm{m} / z 806.5$ $\left(\mathrm{M}+\mathrm{NH}_{4}{ }^{+}\right)$and its reduced form, 3-decaprenyl-1,4-benzoquinol, at $m / z 808.5\left(\mathrm{M}+\mathrm{NH}_{4}^{+}\right)$.

$\mathrm{CoQ}_{10}$ biosynthesis rates were measured as previously described [18], by evaluating incorporation of ${ }^{14} \mathrm{C}$ radiolabelled $4-\mathrm{HB}$.

2.7. Respiratory Chain Activities and ATP Levels. Activities of mitochondrial respiratory chain complexes were measured as described [19]. ATP levels in cells were determined using the ATPlite Luminescence Assay System (PerkinElmer) according to the manufacturer's instructions and using a Victor3 (PerkinElmer) multilabel plate reader.

2.8. ROS Measurement. Intracellular ROS was measured using two different assays. To measure the mitochondrial redox state, we used the mitochondrially targeted redoxsensitive GFP (roGFP) system [20]. A vector expressing ro-GFP was transfected into the different cell lines using Lipofectamine 2000 (Life Technologies). After 48 hours of growth and treatment, fluorescence was measured in a Victor3 (PerkinElmer) multilabel plate reader with an excitation of $405 \mathrm{~nm}$ and emission of $485 \mathrm{~nm}$.

Total oxidant levels were measured using the oxidantsensitive fluorescent probe CM-H2DCFDA (Invitrogen). ROS were detected using CM-H2DCF-DA, a chloromethyl derivative of H2DCFDA. Cells were seeded onto $24 \mathrm{~mm}$ diameter glass coverslips placed in 6-well plates and cultured in the appropriate medium as described above. $30 \mathrm{~min}$ before measurements, cells were loaded with CM-H2DCF-DA $(2.5 \mu \mathrm{M})$ and then washed twice. All the steps were carried out at $37^{\circ} \mathrm{C}$ with $5 \% \mathrm{CO}_{2}$. The chambered coverslips were transferred to a Leica (Wetzlar, Germany) DMI6000B microscope, equipped with a digital camera. Fluorescence was measured in 5-7 random fields per chamber. For each group, 4-6 chambers were analyzed. Fluorescence emission was monitored by using $560 \pm 20 \mathrm{~nm}$ excitation and $645 \pm 37$ $\mathrm{nm}$ emission filter setting. Data were acquired and analyzed using MetaFluor software (Universal Imaging).

2.9. Measurement of Oxygen Consumption by the Seahorse XF24 Extracellular Flux Analyzer. The oxygen consumption rate (OCR) was determined using a Seahorse XF24 Extracellular Flux Analyzer following the manufacturer's instructions. $24 \mathrm{~h}$ before seeding the Seahorse plate, cells were treated with vanillic acid or CoQ. $10^{3}$ cells per well were seeded onto poly-D-lysine-precoated (Sigma) Seahorse 24-well plates for $48 \mathrm{hrs}$. Then, medium was replaced for $2 \mathrm{mM}$ glucose DMEM and cells were incubated with this medium for $24 \mathrm{~h}$. Prior to the measurements, medium was replaced with Seahorse XF base medium supplemented with $2 \mathrm{mM}$ glucose, $2 \mathrm{mM}$ glutamine, and $1 \mathrm{mM}$ sodium pyruvate and incubated for $1 \mathrm{hr}$ at $37^{\circ} \mathrm{C}$ without $\mathrm{CO}_{2}$. OCR was measured under basal conditions and after the sequential addition of oligomycin $(1 \mu \mathrm{M})$, FCCP $(0.2 \mu \mathrm{M})$, rotenone $(1 \mu \mathrm{M})$, and antimycin $\mathrm{A}(2.5 \mu \mathrm{M})$. To normalize respiration rates, cells were harvested and counted after the assay.

2.10. In Silico and Statistical Analyses. The structure of human COQ6 was modelled on that of P. fluorescens parahydroxybenzoate hydroxylase (Protein Data Bank code $1 \mathrm{PBE}$ ) as reported [13]. Statistical analyses were performed as described [21].

\section{Results}

3.1. COQ6 Is Essential for $\mathrm{CoQ}_{10}$ Biosynthesis in Mammalian Cells. Wild-type HEK293 cells were transfected with the CRISPR-Cas9 constructs, and after selection, individual clones were genotyped. All analyzed clones harbored a deletion of 75 nucleotides (Figure 1(a)), which caused a deletion of 25 amino acids (Figure 1(b)) in a region of the protein which participates to the FAD-binding site (Figure 1(c)) and is contained in all three isoforms of human COQ6.

Western blot analysis of the mixed clones did not detect residual COQ6 protein (Figure 1(d)), and when the mutant cDNA was expressed in delta coq6 yeast, VA could not rescue growth in nonfermentable media (not shown). These results indicate that the deletion results in an inactive, unstable protein. From now, we will refer to these cells as COQ6 $\triangle 25$.

$\mathrm{CoQ}_{10}$ levels were markedly reduced in COQ6 $\Delta 25$ cells compared to wild-type cells (Figure 1(e)). Incorporation of ${ }^{14} \mathrm{C}$-labelled 4 -HB was virtually undetectable (Figure 1(f)), indicating that, in analogy with what we observed in COQ4KO cells [22], the residual $\mathrm{CoQ}_{10}$ detected in these cells is not produced endogenously but it is derived from the 

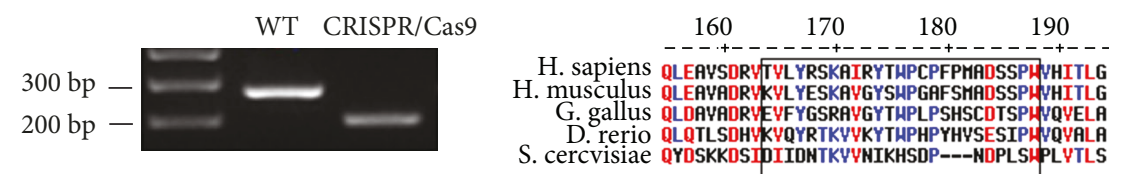

(a)

(b)

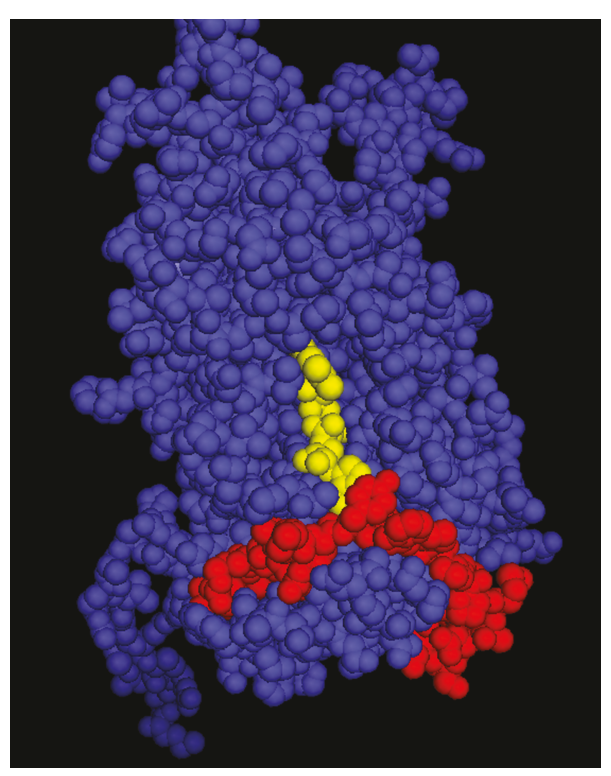

(c)

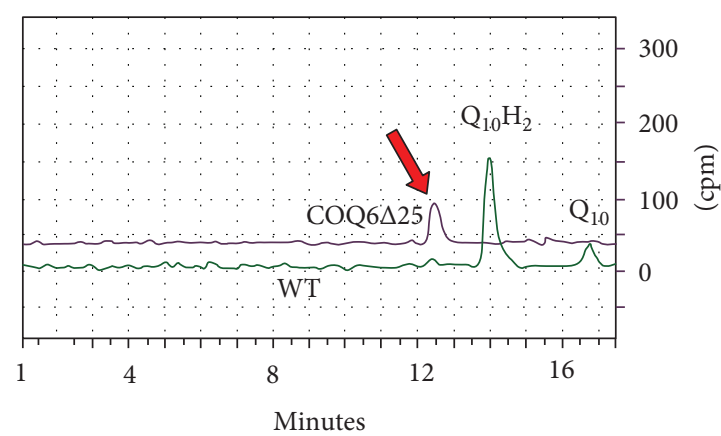

(f)

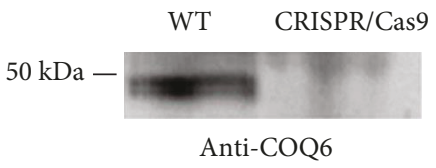

(d)

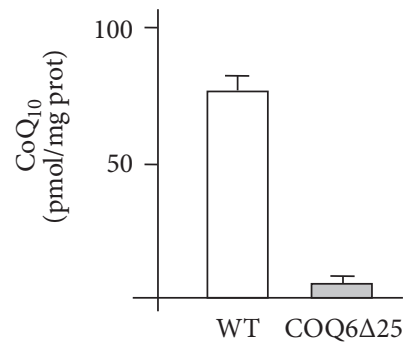

(e)

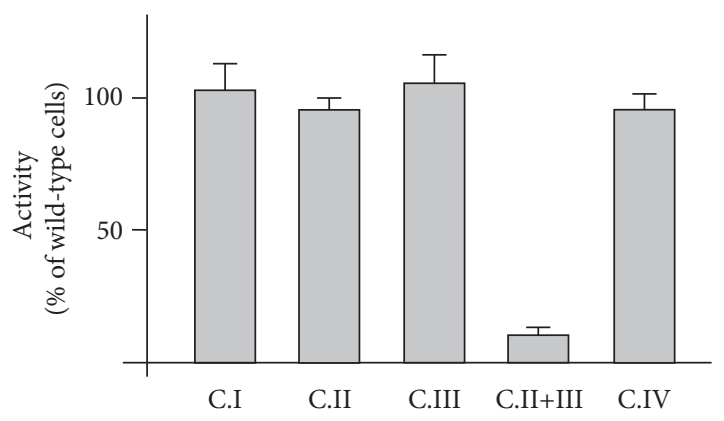

(g)

FIGURE 1: (a) PCR amplification of the COQ6 genomic region targeted by the CRISPR/Cas9 nucleases showing the 75 bp deletion in CRISPR/Cas9-treated cells. (b) Alignment of COQ6 proteins from different species. Boxed are the 25 amino acids affected by the deletion. The numbers refer to the human protein. (c) Three-dimensional structure of human COQ6. In red are the deleted amino acids, and in yellow are the bound FAD molecules. (d) Western blot analysis in wild-type and COQ6 $\Delta 25$ cells. (e) Steady-state CoQ 10 levels in wild-type and COQ6 $\Delta 25$ cells. (f) ${ }^{14} \mathrm{C} 4-\mathrm{HB}$ incorporation in wild-type and COQ6 25 cells. The peaks corresponding to oxidized and reduced $\mathrm{CoQ}_{10}$ are virtually undetectable in COQ6 $\Delta 25$ cells. An additional peak (red arrow) is present in COQ6 25 cells. (g) Respiratory chain enzyme activities normalized to citrate synthase activity of COQ6 $\Delta 25$ cells. Data are expressed as percentage of activity of control cells.

medium. The chromatogram showed an additional radioactive peak present only in COQ6 $\Delta 25$ cells, which eluted faster than $\mathrm{CoQ}_{10}$ (Figure $1(\mathrm{f})$ ).

Activities of individual respiratory chain enzymes were normal; however, combined activity of complexes II and III was markedly reduced in these cells, consistent with severe $\mathrm{CoQ}_{10}$ deficiency (Figure $1(\mathrm{~g})$ ). ATP levels were also markedly reduced (see below). Complex I + III activity was not assayed as results are unreliable in cultured (even when mitochondria-enriched preparations are used), due to the residual high levels of rotenone-insensitive activity [19].

\subsection{COQ6 25 Cells Accumulate 3-Decaprenyl-1,4-} benzoquinone. To characterize the additional product detected in COQ6 $\Delta 25$, we analyzed lipid extracts from WT and COQ $6 \Delta 25$ cells by HPLC-MS. Electrochemical detection confirmed a marked reduction of $\mathrm{CoQ}_{10}$ in COQ6 $\Delta 25$ cells and the presence of an electroactive compound that eluted 


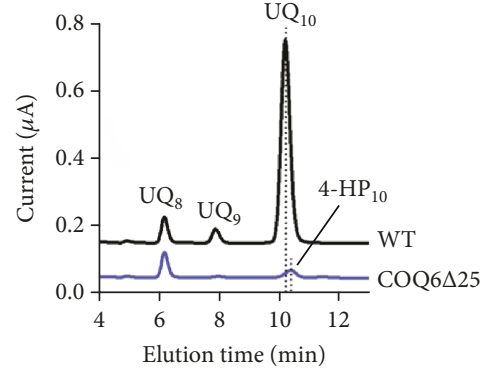

(a)

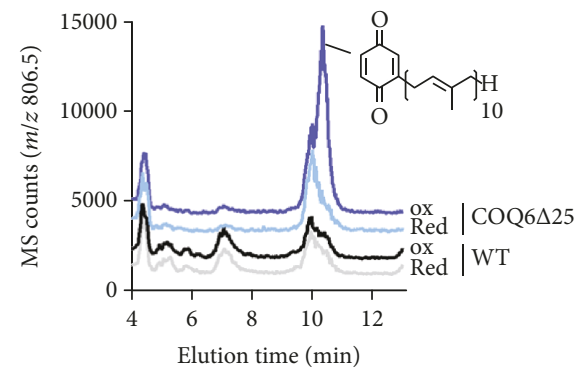

(b)

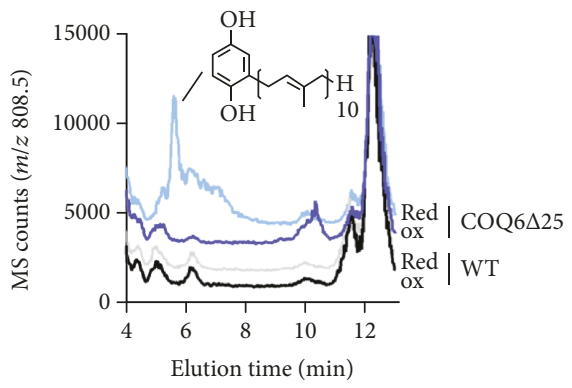

(c)

FIGURE 2: (a) HPLC electrochemical detection analyses (with precolumn electrode in oxidizing mode) of lipid extracts from wild-type (WT) and COQ6 $\triangle 25$ cells $\left(0.2 \mathrm{mg}\right.$ protein) with $\mathrm{UQ}_{8}$ used as standard. $\mathrm{UQ}_{10}$ and $4-\mathrm{HP}_{10}$ have different retention times as shown by the dotted lines. (b, c) Single-ion monitoring ((b) $\mathrm{m} / z$ 806.5, (c) $\mathrm{m} / z$ 808.5) in HPLC mass spectrometry analyses of lipid extracts from WT and COQ6 $\triangle 25$ cells $(0.2 \mu \mathrm{g}$ protein) with the precolumn electrode set in oxidizing mode (ox) or reducing mode (red). The chemical structures of (b) 3-decaprenyl-1,4-benzoquinone and (c) 3-decaprenyl-1,4-benzoquinol are shown.

at $10.4 \mathrm{~min}$, right after $\mathrm{CoQ}_{10}$ (Figure 2(a)). This compound was characterized by HPLC-coupled mass spectrometry, and mass scanning $(\mathrm{m} / \mathrm{z} 600-900)$ showed a prominent ion at 806.5 around $10.4 \mathrm{~min}$ (data not shown). A signal at 10.4 min was indeed specifically obtained in COQ6 $\Delta 25$ cells with single-ion monitoring for $m / z 806.5$ (Figure 2(b)), a mass $\left(\mathrm{M}+\mathrm{NH}_{4}{ }^{+}\right)$compatible with that of 3-decaprenyl1,4-benzoquinone $\left(4-\mathrm{HP}_{10}\right)$. Upon shifting the precolumn electrode to a reducing mode, the signal at $m / z 806.5$ disappeared (Figure 2(b)) and a signal at $m / z 808.5$ appeared at $5.8 \mathrm{~min}$ (Figure 2(c)), consistent with the two-electron reduction of $4-\mathrm{HP}_{10}$. Overall, these data show that the impairment of $\mathrm{CoQ}_{10}$ biosynthesis in COQ6 $\Delta 25$ cells leads to the accumulation of $4-\mathrm{HP}_{10}$, in agreement with the accumulation of $4-\mathrm{HP}_{6}$ previously reported in yeast $\Delta$ coq6 cells [7].

3.3. COQ6 Isoform c Does Not Rescue CoQ ${ }_{10}$ Biosynthesis. At least three different COQ6 isoforms exist in human cells: the most represented transcript (with GenBank accession NM_182476) encodes isoform $a$, but there are two additional transcripts (isoforms $b$ and $c$ ), which are present at lower levels in cells and encode different proteins [8]. We have previously shown that isoform $b$, which contains an alternative first exon (exon 1b) and lacks exon 3, is not active [13]. Isoform $c$ (accession NM_182480) differs from isoform $a$ only for the first exon and is still predicted to contain a mitochondrial-targeting sequence, but it is not clear if it encodes an active enzyme (Figure 3(a)). We employed our model to investigate the role of isoform $c$. Using lentiviral vectors, we expressed either isoform $a$ or isoform $c$ in COQ6KO cells. After selection, cells were incubated in DMEM containing $2 \mathrm{mM}$ glucose for $48 \mathrm{hrs}$. Only isoform $a$ rescued complex II and III activity (and thus CoQ production), whereas isoform $c$ had no effect (Figure 3(b)). We also checked the subcellular localization of isoform $c$ using a C-terminal GFP fusion construct, analogous to what we had previously employed for isoform a. As seen in Figure 3(c), the fusion protein colocalizes with mitochondrially targeted red fluorescent protein (mtRFP), indicating that the lack of complementation is not due to faulty mitochondrial targeting. We noted that some diffuse, faint green florescence can be observed also in the cytosol. This could reflect the fact that, physiologically, a certain proportion of COQ6 isoform $c$ is not imported into mitochondria but it could also be an artifact due to overexpression or to the presence of GFP.

3.4. Vanillic Acid Restores $\operatorname{CoQ}_{10}$ Biosynthesis, Cellular Respiration, and ATP Production in COQ6 25 Cells. VA differs from 4-HB for the presence of a methoxyl group in position C5 (Figure 4(a)). To test the possibility of bypassing the COQ6 defect in mammalian cells, we incubated different cell types with either $\mathrm{CoQ}_{10}$ or VA. We found that VA restored II + III activity in COQ6 $\Delta 25$ cells transduced with the G255R point mutant, but also in cells transformed with the empty vector, indicating that contrary to what happens in yeast, rescue is not restricted to inactive but structurally stable alleles but it occurs also with null mutants. $\mathrm{CoQ}_{10}$ supplementation had a similar effect on II + III activity (Figure 4(b)). Direct measurement of $\mathrm{CoQ}_{10}$ levels confirmed this finding (Figure 4(c)). We noted that the G255R mutant displays relatively high 


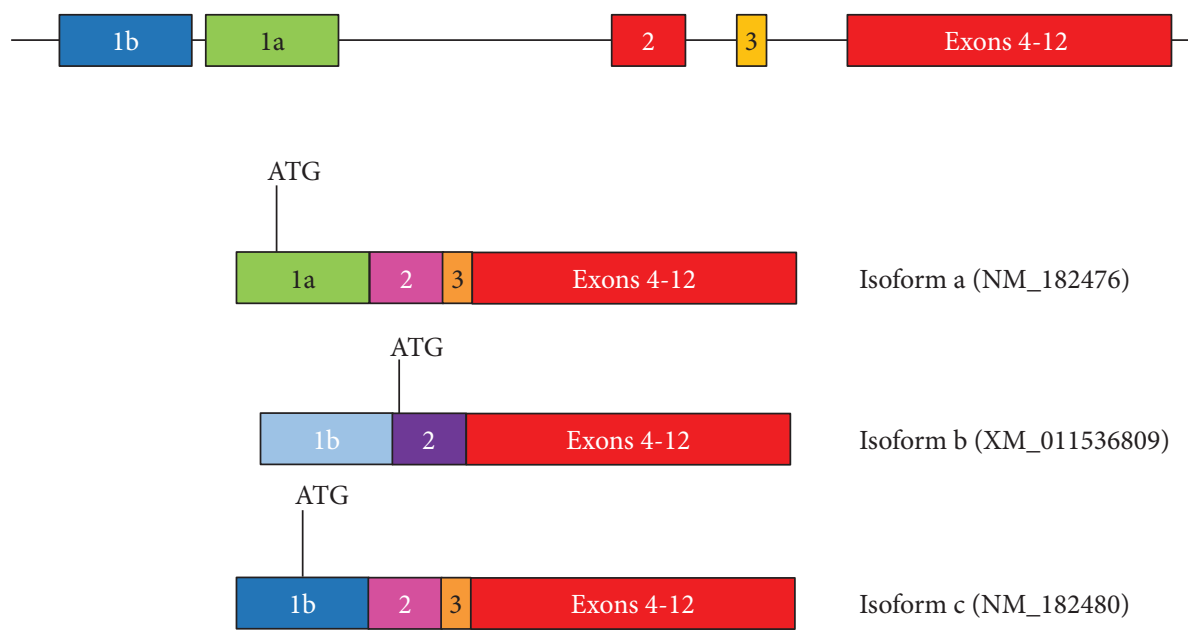

(a)

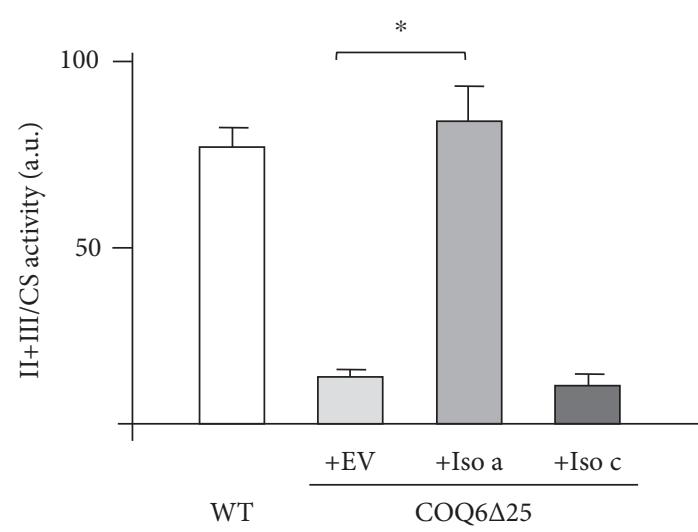

(b)

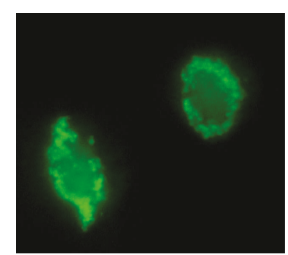

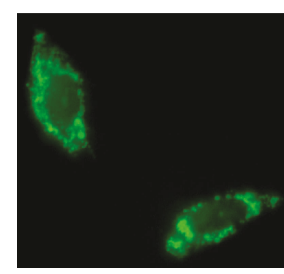

COQ6-Iso-c-GFP
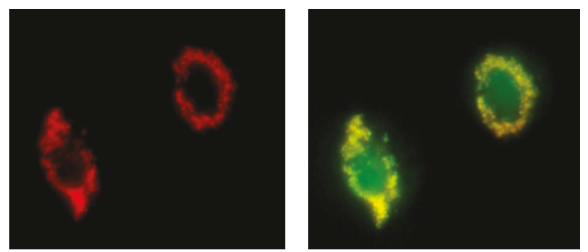

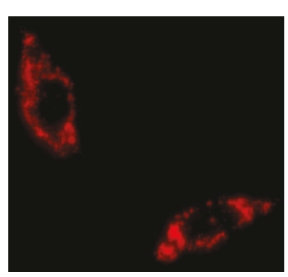

mtRFP

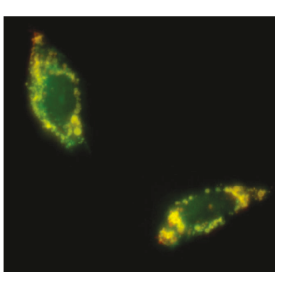

Merge (c)

Figure 3: (a) Schematic representation of the three main COQ6 isoforms. Isoform $a$ is the most widely represented and comprises exon 1a. Isoform $b$ is transcribed from an alternative first exon (exon 1b) which is not translated, and translation starts in exon 2 using a different reading frame compared to those of isoforms $a$ and $c$. Exon 3 is skipped and this allows restoration of the normal reading frame from the $3^{\prime}$ exons. Isoform $c$ is transcribed and translated from exon 1b. (b) Complex II + III activity in wild-type (WT) and COQ6 25 cells transduced with the empty vector (EV), COQ6 isoform $a$ (Iso $a$ ), and COQ6 isoform $c$. ${ }^{*} p<0.05$. (c) HeLa cells stably expressing mtRFP were transiently transfected with COQ6-Iso-c-GFP plasmid expressing GFP fused to the C-terminus of COQ6.

basal II + III activity but this is consistent with the fact that it is a hypomorphic allele [13] and that the lentiviral vector that we are using is probably overexpressing the transgene since it uses the strong CMV promoter. ATP levels were markedly reduced in COQ6 $\Delta 25$ cells, but after VA supplementation, they were virtually normal (Figure 4(d)). VA treatment could also restore coupled respiration in COQ6 $\Delta 25$ cells (Figures $4(\mathrm{e})$ and $4(\mathrm{f})$ ). In untreated cell, this value was about $10 \%$ of the wild type, in line with what we reported for COQ4KO cells. The residual respiration is probably due to the presence of a small amount of exogenous CoQ collected from the serum in cell culture media [22].

3.5. VA but Not CoQ10 Normalizes ROS Production in COQ6 25 Cells. Because of the role of CoQ as an antioxidant, we studied the effect of VA supplementation on ROS production in COQ6 $\Delta 25$ cells. In accordance with previously reported data [23], we did not detect a significant increase of mitochondrial ROS production using mitochondrially targeted ro-GFP (Figure 5(a)). Conversely, when we employed a different system, based on the $\mathrm{CM}-\mathrm{H}_{2} \mathrm{DCFDA}$ probe, 
<smiles>O=C(O)c1ccc(O)cc1</smiles><smiles>COc1cc(C(=O)O)ccc1O</smiles>

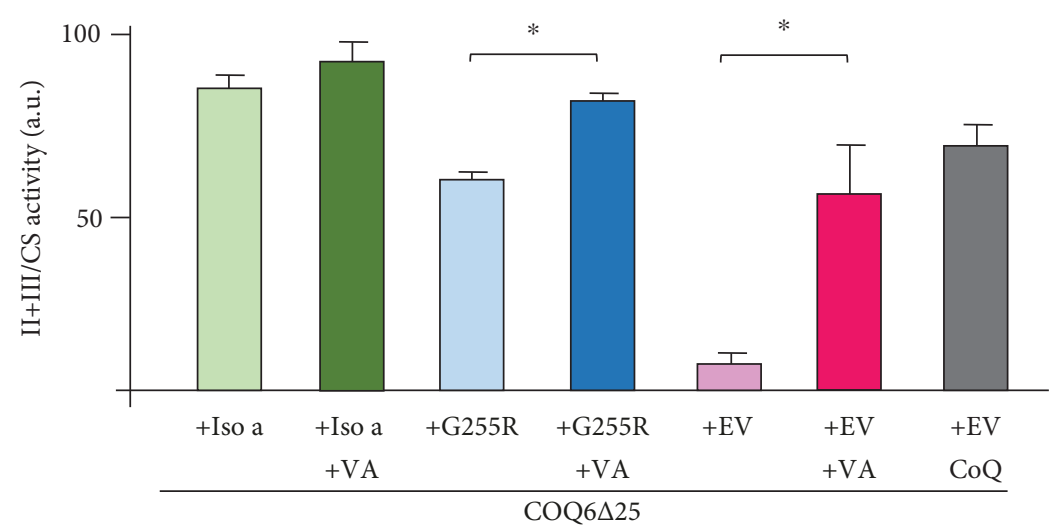

(a)

(b)
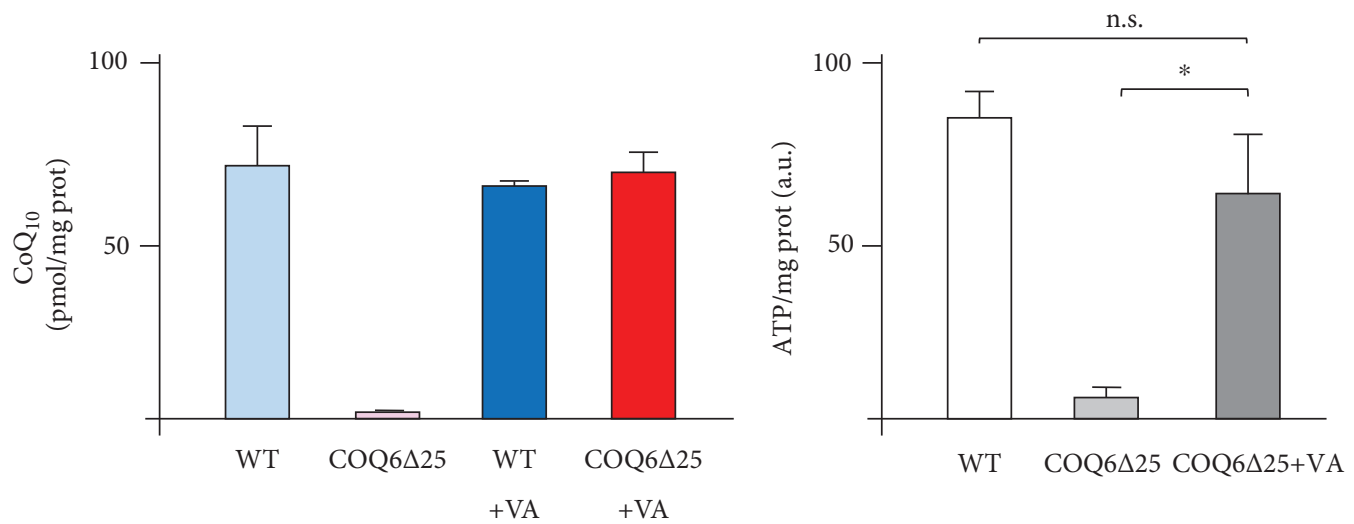

(c)

(d)
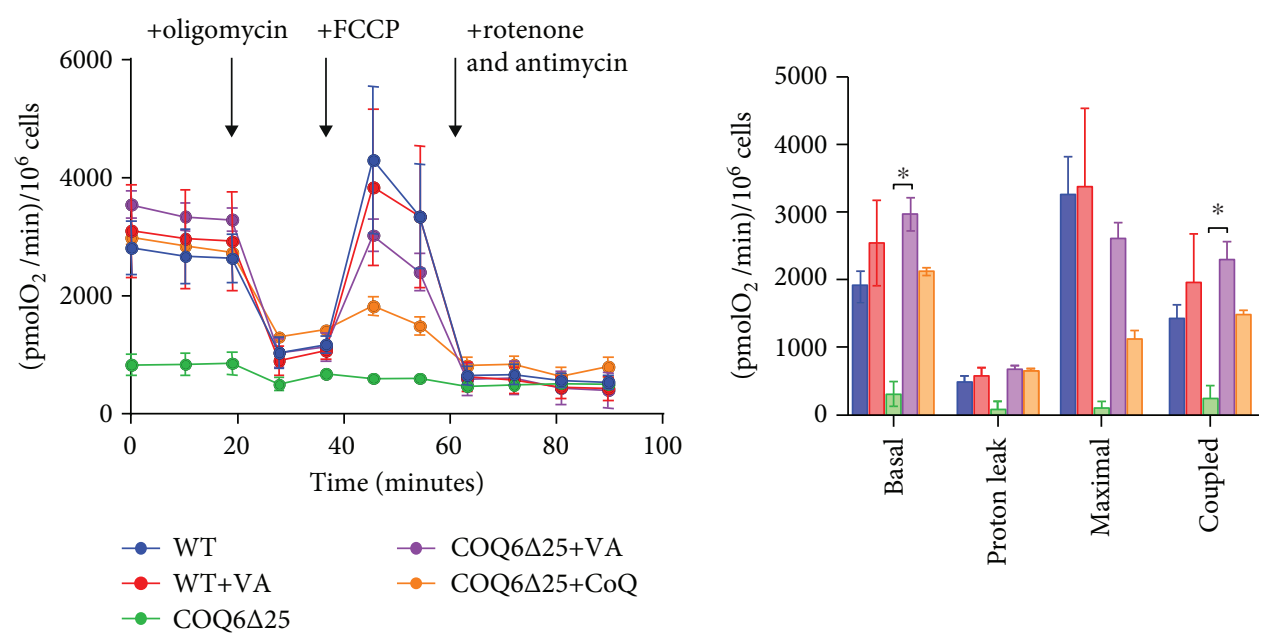

(e)

(f)

Figure 4: (a) Structure of VA compared to 4-HB the physiological precursor of CoQ. (b) Complex II + III activity in COQ6 25 cells transduced with COQ6 isoform $a$ (Iso $a$ ), the G255R mutant, and the empty vector (EV), before and after supplementation with VA or $\mathrm{CoQ}_{10}$; n.s.: nonsignificant. (c) Steady-state CoQ10 levels and (d) ATP levels in WT and COQ6 25 cells after supplementation with VA for 48 hours; a.u.: arbitrary units. (e) Oxygen consumption rate (OCR) profiles in WT and COQ6 25 cells treated with VA or CoQ, determined using a Seahorse XF24 Extracellular Flux Analyzer. The arrows indicate the addition of the individual inhibitors. (f) The same data represented as histograms.

which measures total cellular ROS [24], we found increased levels in the COQ6 25 cells. VA treatment was able to decrease ROS to basal levels, while CoQ supplementation was only partially effective (Figures 5(b) and 5(c)).

\section{Discussion}

Bypass therapy is a promising alternative to conventional $\mathrm{CoQ}$ supplementation for patients with primary CoQ 


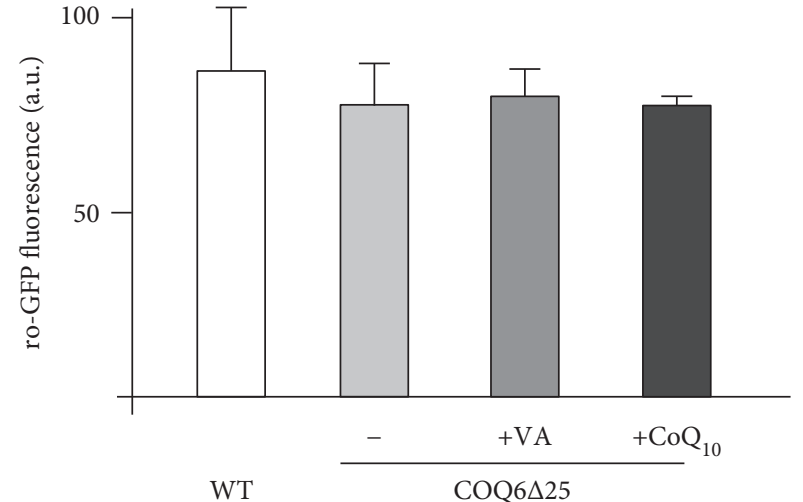

(a)

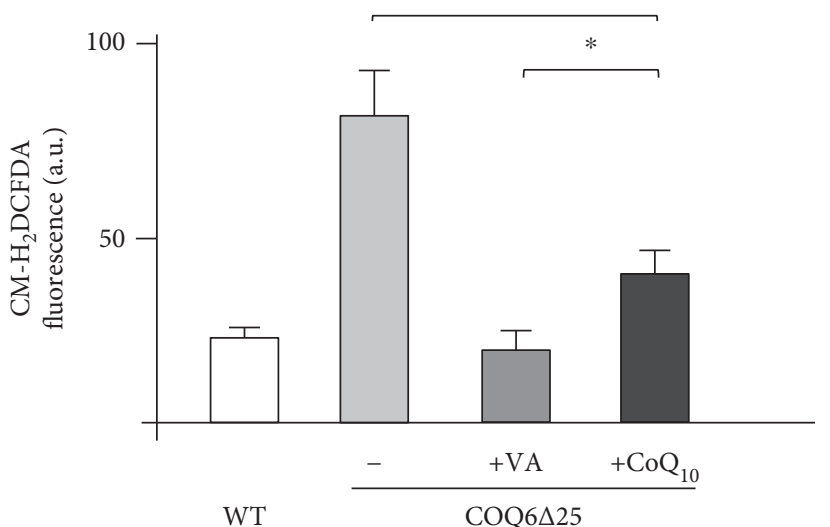

(b)

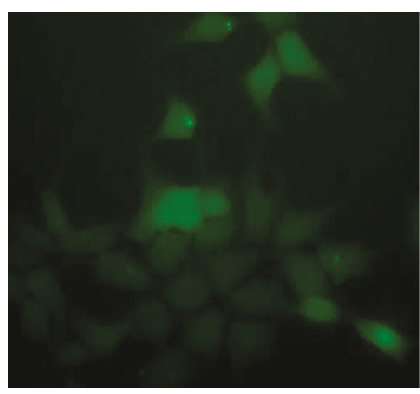

WT

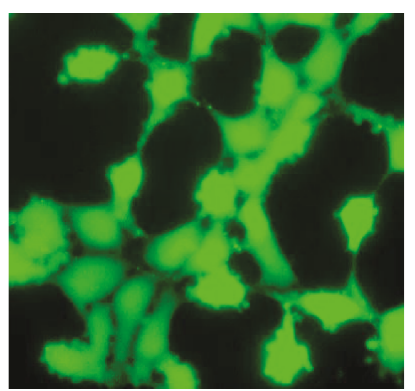

COQ6 $\triangle 25$

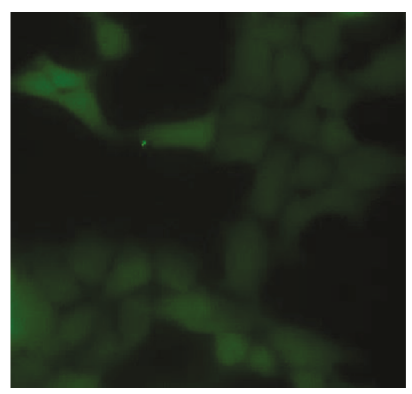

COQ6 $425+\mathrm{VA}$

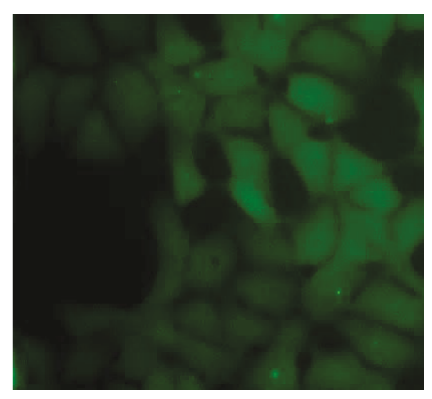

COQ6 $\Delta 25+C o Q 10$

(c)

FIGURE 5: (a) Mitochondrial ROS evaluated using mitochondrially targeted ro-GFP. (b, c) Total cellular ROS evaluated using the $\mathrm{CM}-\mathrm{H}_{2}$ DCFDA probe (see methods for details). (c) Representative photomicrographs of the same cells (magnification $\times 40$ ).

deficiency and has been successfully tested in mouse models of COQ7 and COQ9 defects $[25,26]$ and in cells of patients with COQ7 mutations [27, 28]. In particular, mice with a conditional ablation of the Coq7 gene (which encodes the C6-hydroxylase catalyzing the penultimate step of CoQ biosynthesis) at 2 months of age developed severe, multiorgan CoQ deficiency, which lead to death after 9 months. If these animals were treated immediately before death with 2,4dihydroxybenzoate (2,4-DHB), a compound similar to VA which can bypass the Coq7 defect, CoQ biosynthesis was restored and the animals recovered virtually all symptoms and displayed a normal lifespan [26].

In this work, we have generated a cell line lacking functional COQ6 using a genome-editing approach. We are aware that this model has some limitations. We obtained an in-frame deletion, which could still produce some folded protein (below the threshold of detectability of our assays), and we could not rule out off-target effects, even though reexpression of the wild-type cDNA corrected the biochemical phenotype of these cells.

Using this model, we showed that VA can restore $\mathrm{CoQ}_{10}$ endogenous biosynthesis in human cells lacking COQ6. VA is a very attractive compound for use as a therapeutic agent in patients for several reasons. In vivo, it can be produced in the liver through oxidation of vanillin $[29,30]$, which is commonly used as a flavoring agent by the food industry. Vanillin is considered nontoxic and safe for human use by the FDA and has a good bioavailability. VA can cross the blood brain barrier efficiently [31], thus overcoming one of the major limitations of oral CoQ supplementation.

Moreover, we show that in our cellular model, VA can correct cytosolic ROS production, which is increased in COQ6 $\Delta 25$ cells and is only partially reduced by CoQ supplementation, confirming the observation that in C. elegans reactivation of endogenous biosynthesis is superior to CoQ supplementation [32]. These data are not in contrast with previous results in patients' cultured fibroblasts [23]. Exogenous $\mathrm{CoQ}_{10}$ enters the cells through the brefeldin A-sensitive endo-exocytic pathway, and it is mainly incorporated into the endolysosomal fraction and also in mitochondriaassociated membranes and mitochondria. The better performance of VA compared to CoQ could be explained by the fact that VA restores the production of endogenous CoQ, which is then delivered to the appropriate subcellular compartments at optimal concentration.

Our work highlights other important points regarding COQ6 function in mammalian cells. COQ6 isoform $c$ cannot rescue CoQ biosynthesis when expressed in COQ6 25 cells, suggesting that it does not encode an active protein. This finding is critical for the correct interpretation of genomic analyses in patients. In fact, COQ6 exon $1 \mathrm{~b}$ is targeted by most exome analysis kits and the gnomAD database (http://gnomad.broadinstitute.org/gene/ENSG00000119723) lists several possible loss-of-function mutations within this 


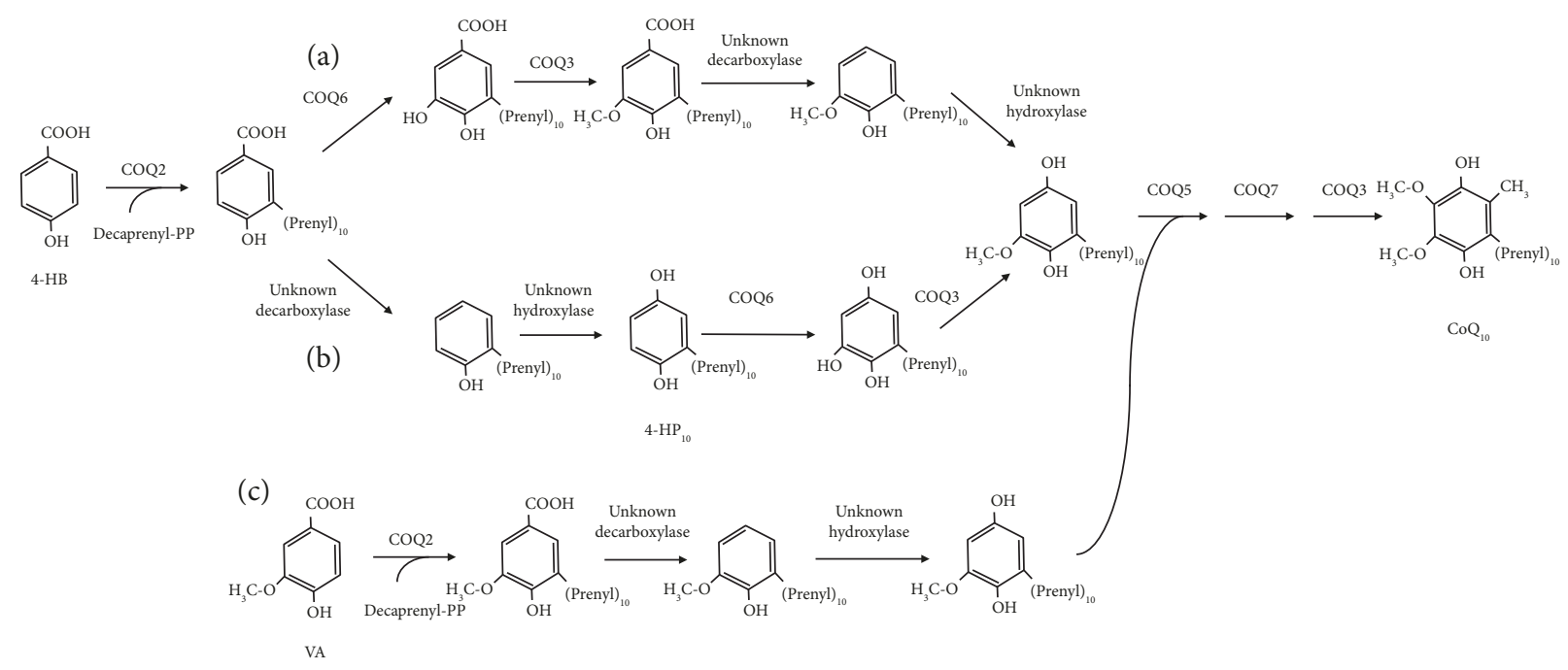

Figure 6: Proposed models of the $\mathrm{CoQ}_{10}$ biosynthetic pathway in mammals showing two alternative sequences of reactions (the decaprenyl chain is abbreviated as R). Path (a) corresponds to the traditional model in which COQ6 acts after the condensation of the ring with the isoprene tail, while path (b) shows the unknown decarboxylase and hydroxylase (in blue) acting before COQ6, consistent with the accumulation of $4-\mathrm{HP}_{10}$ in COQ6-deficient cells. Path (c) depicts the same pathway when VA is employed instead of 4-HB. Biosynthesis can occur even in the absence of COQ6 because carbon C5 of the ring is already bound to a methoxyl group in VA.

exon. One of them NM_182480:c.41G>A p.(Trp14*) occurs with a minor allelic frequency of 0.05 in Africans and is present also in the homozygous state in apparently normal individuals. Overall, these observations indicate that COQ6 isoforms $b$ and $c$ are not essential and are not involved in CoQ deficiency. A regulatory function has been postulated for other inactive isoforms of COQ genes [33-35], but to date, no clear proof of these hypotheses has been provided yet.

The exact order of reactions that carry out the modifications of the aromatic ring of CoQ is still unclear in eukaryotes. Generally accepted models indicate that the C5 hydroxylation catalyzed by COQ6 is the first reaction to occur after the condensation of $4-\mathrm{HB}$ with the polyisoprene tail [36]. However, the fact that COQ6 knockout cells (both human and yeast) accumulate 4-HP, a compound that is decarboxylated and hydroxylated in position $\mathrm{C} 1$ of the ring, indicates that these reactions (which are carried out by still unidentified enzymes) occur before or independently on C5 hydroxylation. Furthermore, this result also confirms the notion that $\mathrm{C} 1$ hydroxylation is not catalyzed by COQ6 [7]. The identification of the enzymes that catalyze these biosynthetic steps will be critical to validate this hypothesis. Figure 6 depicts a possible model of CoQ biosynthesis in mammals according to our data.

$\mathrm{VA}$ was able to restore biosynthesis even in the presence of a null mutant, implying that, contrary to yeast, mammalian cells can assemble the biosynthetic complex even in the absence of COQ6. Therefore, data obtained in yeast about complex assembly and stability should be extrapolated with caution to mammalian cells.

An open issue is whether all COQ6 mutations could be responsive to $\mathrm{VA}$. In the case of COQ7, the response to bypass therapy with $2,4-\mathrm{DHB}$ was more evident when CoQ biosynthesis was severely impaired, rather than when the defect was relatively mild [28]. In the case of COQ6, VA was effective in both situations (CoQ biosynthesis was virtually absent in COQ6 $\Delta 25$ as in COQ7KO cells, while the biosynthetic defect in cells expressing the G255R mutant was similar to that found in cells with the mild COQ7 [M103T+L111P] allele). This peculiar behavior of COQ7 mutants was attributed to the fact that 2,4-DHB has also an inhibitory action on CoQ biosynthesis [28]. Conversely, VA apparently has no inhibitory effects on the pathway and it is reported to stimulate biosynthesis of other COQ proteins [11]. We have tested the majority of known human mutations in a yeast model, and they all appeared to be responsive to VA [13]. Nevertheless, before attempting to treat patients with VA, one should consider to assay the efficacy of the compound in cell lines (primary fibroblasts or lymphoblastoid cells) obtained directly from the patient.

\section{Data Availability}

The data used to support the findings of this study are available from the corresponding author upon request.

\section{Conflicts of Interest}

None of the authors have conflicts of interest to disclose.

\section{Authors' Contributions}

Gloria Brea-Calvo and Leonardo Salviati are authors that share senior authorship.

\section{Acknowledgments}

This work was funded by Fondazione Telethon Grant $14187 \mathrm{c}$ (to L.S.), by grants from Fondazione IRP Città della Speranza (to L.S., E.T., and M.C.), by Fondation pour la Recherche 
Médicale (grant number "DPM20121125553"), by Agence Nationale de la Recherche grant pABACoQ "ANR-11JSV8-002" (to F.P.), by Instituto de Salud Carlos III PI17/01286 FIS grant, by Junta de Andalucí a Proyecto de Excelencia CTS943, and by the EU FEDER program (to P.N.).

\section{References}

[1] M. Turunen, J. Olsson, and G. Dallner, "Metabolism and function of coenzyme Q," Biochimica et Biophysica Acta Biomembranes, vol. 1660, no. 1-2, pp. 171-199, 2004.

[2] J. A. Stefely and D. J. Pagliarini, "Biochemistry of mitochondrial coenzyme Q biosynthesis," Trends in Biochemical Sciences, vol. 42, no. 10, pp. 824-843, 2017.

[3] L. A. Payet, M. Leroux, J. C. Willison, A. Kihara, L. Pelosi, and F. Pierrel, "Mechanistic details of early steps in coenzyme Q biosynthesis pathway in yeast," Cell Chemical Biology, vol. 23, no. 10, pp. 1241-1250, 2016.

[4] J. A. Stefely, N. W. Kwiecien, E. C. Freiberger et al., "Mitochondrial protein functions elucidated by multi-omic mass spectrometry profiling," Nature Biotechnology, vol. 34, no. 11, pp. 1191-1197, 2016.

[5] M. A. Desbats, V. Morbidoni, M. Silic-Benussi et al., "The COQ2 genotype predicts the severity of coenzyme $\mathrm{Q}_{10}$ deficiency," Human Molecular Genetics, vol. 25, no. 19, pp. 4256-4265, 2016.

[6] B. Marbois, P. Gin, M. Gulmezian, and C. F. Clarke, "The yeast Coq4 polypeptide organizes a mitochondrial protein complex essential for coenzyme Q biosynthesis," Biochimica et Biophysica Acta - Molecular and Cell Biology of Lipids, vol. 1791, no. 1, pp. 69-75, 2009.

[7] M. Ozeir, U. Muhlenhoff, H. Webert, R. Lill, M. Fontecave, and F. Pierrel, "Coenzyme Q biosynthesis: Coq6 is required for the C5-hydroxylation reaction and substrate analogs rescue Coq6 deficiency," Chemistry \& Biology, vol. 18, no. 9, pp. 1134-1142, 2011.

[8] S. F. Heeringa, G. Chernin, M. Chaki et al., "COQ6 mutations in human patients produce nephrotic syndrome with sensorineural deafness," The Journal of Clinical Investigation, vol. 121, no. 5, pp. 2013-2024, 2011.

[9] M. Alcázar-Fabra, E. Trevisson, and G. Brea-Calvo, "Clinical syndromes associated with coenzyme $\mathrm{Q}_{10}$ deficiency," Essays in Biochemistry, vol. 62, no. 3, pp. 377-398, 2018.

[10] M. J. Falk, E. Polyak, Z. Zhang et al., "Probucol ameliorates renal and metabolic sequelae of primary CoQ deficiency in Pdss2 mutant mice," EMBO Molecular Medicine, vol. 3, no. 7, pp. 410-427, 2011.

[11] D. Herebian, L. C. Lopez, and F. Distelmaier, "Bypassing human $\mathrm{CoQ}_{10}$ deficiency," Molecular Genetics and Metabolism, vol. 123, no. 3, pp. 289-291, 2018.

[12] F. Pierrel, "Impact of chemical analogs of 4-hydroxybenzoic acid on coenzyme $\mathrm{Q}$ biosynthesis: from inhibition to bypass of coenzyme Q deficiency," Frontiers in Physiology, vol. 8, article 436, 2017.

[13] M. Doimo, E. Trevisson, R. Airik et al., "Effect of vanillic acid on COQ6 mutants identified in patients with coenzyme $\mathrm{Q}_{10}$ deficiency," Biochimica et Biophysica Acta - Molecular Basis of Disease, vol. 1842, no. 1, pp. 1-6, 2014.

[14] J. M. Lopez-Martin, L. Salviati, E. Trevisson et al., "Missense mutation of the COQ2 gene causes defects of bioenergetics and de novo pyrimidine synthesis," Human Molecular Genetics, vol. 16, no. 9, pp. 1091-1097, 2007.

[15] R. Montioli, M. A. Desbats, S. Grottelli et al., "Molecular and cellular basis of ornithine $\delta$-aminotransferase deficiency caused by the V332M mutation associated with gyrate atrophy of the choroid and retina," Biochimica et Biophysica Acta Molecular Basis of Disease, vol. 1864, no. 11, pp. 36293638, 2018.

[16] S. Cipolat, O. M. de Brito, B. Dal Zilio, and L. Scorrano, "OPA1 requires mitofusin 1 to promote mitochondrial fusion," Proceedings of the National Academy of Sciences of the United States of America, vol. 101, no. 45, pp. 15927-15932, 2004.

[17] M. Ozeir, L. Pelosi, A. Ismail, C. Mellot-Draznieks, M. Fontecave, and F. Pierrel, "Coq6 is responsible for the C4-deamination reaction in coenzyme $\mathrm{Q}$ biosynthesis in Saccharomyces cerevisiae," The Journal of Biological Chemistry, vol. 290, no. 40, pp. 24140-24151, 2015.

[18] L. Salviati, E. Trevisson, M. A. Rodriguez Hernandez et al., "Haploinsufficiency of COQ4 causes coenzyme $\mathrm{Q}_{10}$ deficiency," Journal of Medical Genetics, vol. 49, no. 3, pp. 187191, 2012.

[19] M. Spinazzi, A. Casarin, V. Pertegato, M. Ermani, L. Salviati, and C. Angelini, "Optimization of respiratory chain enzymatic assays in muscle for the diagnosis of mitochondrial disorders," Mitochondrion, vol. 11, no. 6, pp. 893-904, 2011.

[20] G. T. Hanson, R. Aggeler, D. Oglesbee et al., "Investigating mitochondrial redox potential with redox-sensitive green fluorescent protein indicators," The Journal of Biological Chemistry, vol. 279, no. 13, pp. 13044-13053, 2004.

[21] C. Cerqua, V. Morbidoni, M. A. Desbats et al., "COX16 is required for assembly of cytochrome c oxidase in human cells and is involved in copper delivery to COX2," Biochimica et Biophysica Acta - Bioenergetics, vol. 1859, no. 4, pp. 244252, 2018.

[22] V. Giorgio, M. Schiavone, C. Galber et al., "The idebenone metabolite QS10 restores electron transfer in complex I and coenzyme Q defects," Biochimica et Biophysica Acta Bioenergetics, vol. 1859, no. 9, pp. 901-908, 2018.

[23] C. M. Quinzii, L. C. Lopez, R. W. Gilkerson et al., "Reactive oxygen species, oxidative stress, and cell death correlate with level of $\mathrm{CoQ}_{10}$ deficiency," The FASEB Journal, vol. 24, no. 10, pp. 3733-3743, 2010.

[24] A. R. Rosenkranz, S. Schmaldienst, K. M. Stuhlmeier, W. Chen, W. Knapp, and G. J. Zlabinger, "A microplate assay for the detection of oxidative products using $2^{\prime}, 7^{\prime}$-dichlorofluorescin-diacetate," Journal of Immunological Methods, vol. 156, no. 1, pp. 39-45, 1992.

[25] A. Hidalgo-Gutiérrez, E. Barriocanal-Casado, M. Bakkali et al., " $\beta$-RA reduces DMQ/CoQ ratio and rescues the encephalopathic phenotype in Coq9 $9^{R 239 X}$ mice," EMBO Molecular Medicine, vol. 11, no. 1, article e9466, 2019.

[26] Y. Wang, D. Oxer, and S. Hekimi, "Mitochondrial function and lifespan of mice with controlled ubiquinone biosynthesis," Nature Communications, vol. 6, no. 1, article 6393, 2015.

[27] C. Freyer, H. Stranneheim, K. Naess et al., "Rescue of primary ubiquinone deficiency due to a novel COQ7 defect using 2,4dihydroxybensoic acid," Journal of Medical Genetics, vol. 52, no. 11, pp. 779-783, 2015.

[28] Y. Wang, C. Smith, J. S. Parboosingh, A. Khan, M. Innes, and S. Hekimi, "Pathogenicity of two COQ7 mutations and responses to 2,4-dihydroxybenzoate bypass treatment," 
Journal of Cellular and Molecular Medicine, vol. 21, no. 10, pp. 2329-2343, 2017.

[29] F. A. Muskiet and A. Groen, "Urinary excretion of conjugated homovanillic acid, 3,4-dihydroxyphenylacetic acid, phydroxyphenylacetic acid, and vanillic acid by persons on their usual diet and patients with neuroblastoma," Clinical Chemistry, vol. 25, no. 7, pp. 1281-1284, 1979.

[30] G. Panoutsopoulos and C. Beedham, "Enzymatic oxidation of vanillin, isovanillin and protocatechuic aldehyde with freshly prepared guinea pig liver slices," Cellular Physiology and Biochemistry, vol. 15, no. 1-4, pp. 089-098, 2005.

[31] M. Gitzinger, C. Kemmer, D. A. Fluri, M. Daoud El-Baba, W. Weber, and M. Fussenegger, "The food additive vanillic acid controls transgene expression in mammalian cells and mice," Nucleic Acids Research, vol. 40, no. 5, article e37, 2012.

[32] F. Gomez, R. Saiki, R. Chin, C. Srinivasan, and C. F. Clarke, "Restoring de novo coenzyme Q biosynthesis in Caenorhabditis elegans coq-3 mutants yields profound rescue compared to exogenous coenzyme Q supplementation," Gene, vol. 506, no. 1, pp. 106-116, 2012.

[33] A. Casarin, J. C. Jimenez-Ortega, E. Trevisson et al., "Functional characterization of human COQ4, a gene required for coenzyme Q10 biosynthesis," Biochemical and Biophysical Research Communications, vol. 372, no. 1, pp. 35-39, 2008.

[34] T. P. T. Nguyen, A. Casarin, M. A. Desbats et al., "Molecular characterization of the human COQ5 C-methyltransferase in coenzyme $\mathrm{Q}_{10}$ biosynthesis," Biochimica et Biophysica Acta Molecular and Cell Biology of Lipids, vol. 1841, no. 11, pp. 1628-1638, 2014.

[35] R. Saiki, A. L. Lunceford, Y. Shi et al., "Coenzyme $Q_{10}$ supplementation rescues renal disease in $P d s s 2^{k d / k d}$ mice with mutations in prenyl diphosphate synthase subunit 2," American Journal of Physiology-Renal Physiology, vol. 295, no. 5, pp. F1535-F1544, 2008.

[36] M. Kawamukai, "Biosynthesis of coenzyme Q in eukaryotes," Bioscience, Biotechnology, and Biochemistry, vol. 80, no. 1, pp. 23-33, 2016. 


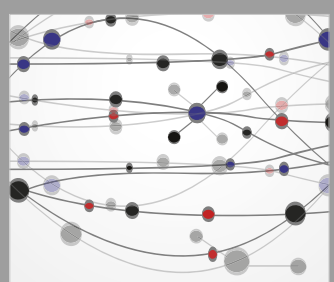

The Scientific World Journal
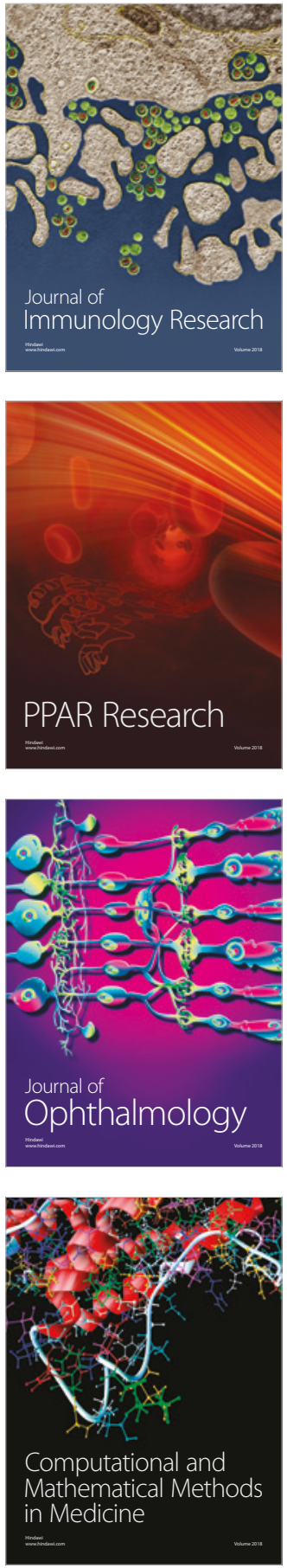

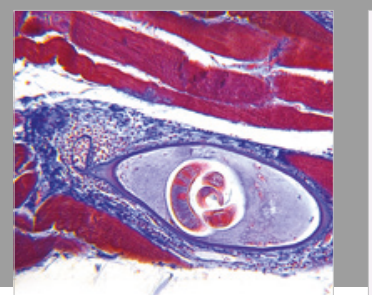

Gastroenterology Research and Practice

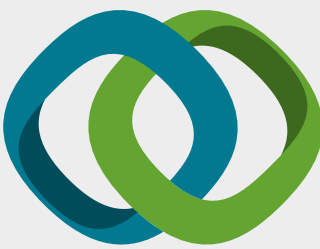

\section{Hindawi}

Submit your manuscripts at

www.hindawi.com
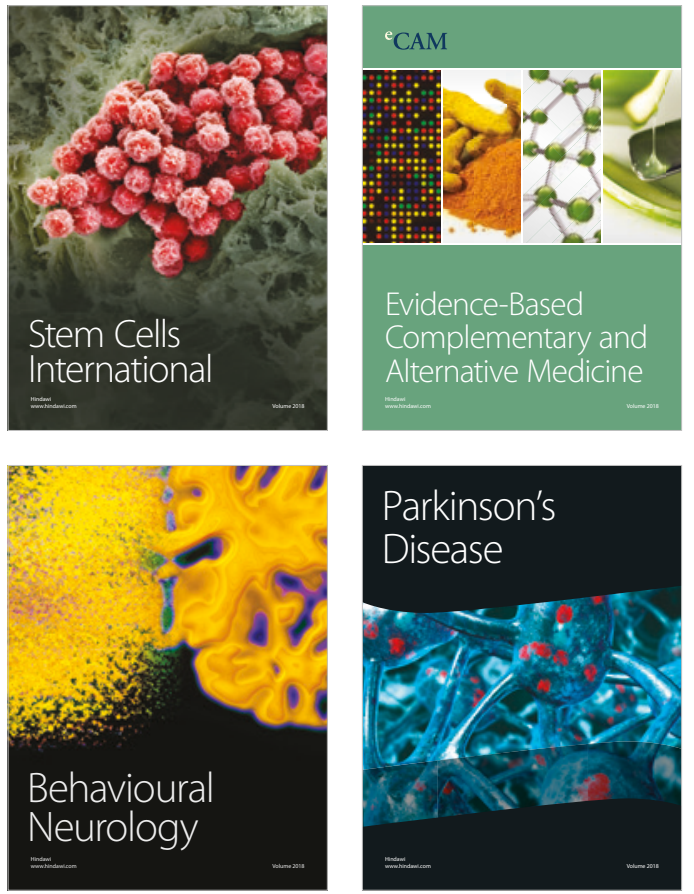

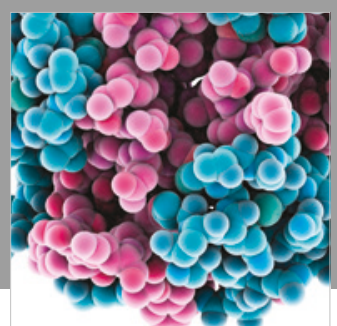

ournal of

Diabetes Research

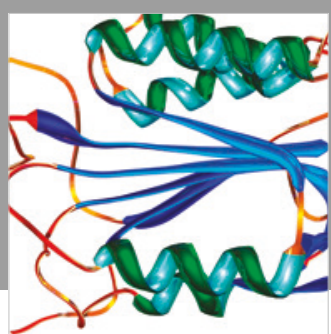

Disease Markers
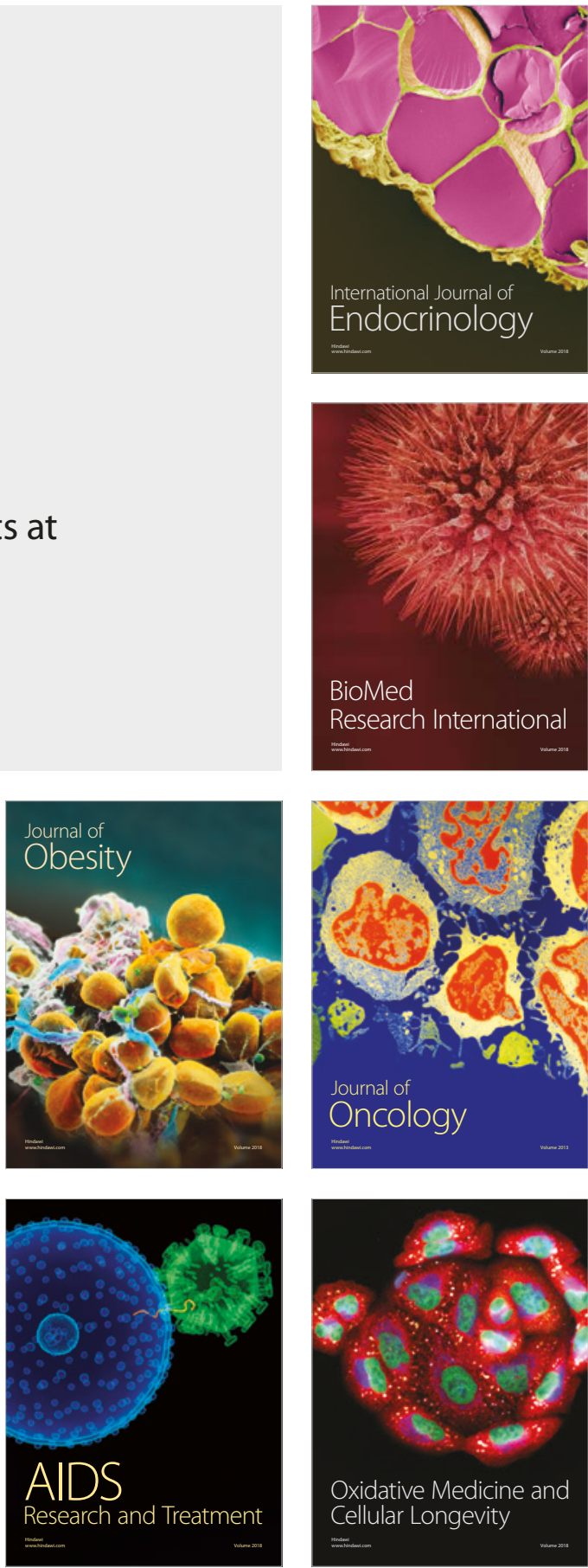